Article

\title{
Academic Relational Civility as a Key Resource for Sustaining Well-Being
}

\author{
Annamaria Di Fabio ${ }^{1, *}$ and Maureen E. Kenny ${ }^{2}$ \\ 1 Department of Education and Psychology (Psychology Section), University of Florence, Via di San Salvi, \\ 12 Complesso di San Salvi, Padiglione 26, 50135 Firenze, Italy \\ 2 Lynch School of Education, Boston College, Chestnut Hill, MA 02467, USA; maureen.kenny@bc.edu \\ * Correspondence: adifabio@psico.unifi.it; Tel.: +39(0)55-2055850; Fax: +39(0)55-2756134
}

Received: 24 April 2018; Accepted: 5 June 2018; Published: 7 June 2018

\begin{abstract}
In the 21st century, which has been characterized by complexity, instability, and continuous change, the well-being of individuals is threatened. The health and well-being of individuals are recognized as one of the 17 sustainable development goals of the United Nations. From a primary prevention perspective, physical and psychological health can be augmented through the early identification and promotion of key psychological resources that sustain well-being across one's lifetime. With that goal in mind, the present study explored potential relationships between academic relational civility and both hedonic (positive affect, negative affect, and life satisfaction) and eudaimonic well-being (meaning in life and flourishing), controlling for the effect of personality traits among university students. The Big Five Questionnaire (BFQ), the Academic Relational Civility Scale (ARCS), the Positive and Negative Affect Schedule (PANAS), the Satisfaction With Life Scale (SWLS), the Meaning in Life Measure (MLM), and the Flourishing Scale (FS), were administered to 241 Italian university students. Regression analyses identified that academic relational civility contributed significantly to hedonic and eudaimonic well-being beyond the contribution of stable personality factors. Academic relational civility may represent one psychological resource for supporting and sustaining hedonic and eudaimonic well-being, suggesting the need for further research and intervention.
\end{abstract}

Keywords: academic relational civility; hedonic well-being; eudaimonic well-being; personality traits; psychology of sustainability

\section{Introduction}

The complexity [1], instability, insecurity, turmoil and continuous change [2-8] that characterize life in contemporary society pose significant risks to the well-being of individuals [9]. With concern for the large number of people worldwide who suffer from poor physical and mental health, the United Nations [10] has included the attainment of good health and well-being among their 17 sustainable development goals. In this regard, sustainability extends beyond a concern for economic and ecological resources to a concern for enhancing the psychological and contextual resources that can maximize well-being for all [11,12].

The World Health Organization (WHO) [13] defines health as "a state of complete physical, mental, spiritual and social well-being and not merely the absence of disease or infirmity." This comprehensive definition emphasizes a view of healthy people as, not merely free of serious problems, but as resilient and fully flourishing $[9,14,15]$.

Positive psychology [16,17] and primary prevention [18] embrace research and practice agendas directed towards the promotion of health and well-being, including explicitly, the development of resources for resilience and implicitly, the psychology of sustainability [11,12]. Positive psychology 
identifies two kinds of well-being: hedonic [19] and eudaimonic well-being [20,21]. Hedonic well-being refers to the presence of positive affect over negative affect [19] and to the cognitive appraisal of one's life as satisfying [22]. Eudaimonic well-being goes beyond the possession of positive feelings and satisfaction and refers to optimal functioning and a high level of self-realization [20], life meaning [23], purposefulness [21], and the ability to flourish [24]. Flourishing is reflective of the UN and WHO emphases on optimal functioning across multiple life domains and entails a maximal level of social and psychological prosperity based on one's perceived success in relationships, one's level of self-esteem, and one's sense of purpose and optimism. More specifically, flourishing entails great interest and engagement in daily activities that provide a deep sense of meaning and purpose and through which one experiences feelings of competence, actively contributes to the happiness and well-being of others, enjoys supportive, respectful, and rewarding social relationships, and feels optimistic about one's future [24]. Prior research has found personality traits to be associated with both hedonic [14,25-28] and eudaimonic well-being [14,29-31]. Personality traits are considered to be generally fixed or stable [32], however, and researchers have sought to identify factors that are modifiable and can be developed though interventions to promote well-being $[13,14,33,34]$.

The concern in positive psychology [16,17] for the promotion of well-being, both hedonic and eudaimonic, is aligned with the agenda of primary prevention for the promotion of resources and strengths to foster well-being $[9,13,35]$, as well as the WHO $[13,15]$ and the UN Sustainable Development Goals [10] concern for human flourishing. Among the psychological variables connected to well-being, the experience of positive and supportive relationships in promoting well-being at work and across life in general has been well established Blustein $[2,13,36-40]$. Positive relationships within organizations can promote well-being that extends beyond the workplace, impacting other life contexts [2,41]. In this regard, the university is no different than other organizational settings, with relational quality affecting both well-being and student academic success. Cotton, Dollard, and de Jong [42] emphasized the responsibility of the university to nurture the well-being, satisfaction and performance of students. Psychosocial work characteristics of the university context, including the amount and quality of social interaction [43], have been associated with student academic performance as mediated by student well-being and satisfaction [42]. Research has also found that university student reports of psychosocial well-being are associated with their perceptions of interpersonal relationships, including the capacity of those relationships as a source of meaning and fulfillment [44]. Furthermore, social support provided by parents, teachers and friends is also consistently related to psychological well-being among university students [45-47]. While the benefits of positive relationships appear robust, academic incivility, including any words or behaviors that interfere with the climate for teaching and learning, appears to threaten student well-being and academic progress [48]. Reports of academic incivility on university campuses across many regions of the world have increased in recent times as a function of enhanced competition for economic and social resources and increased diversity in terms of ethnicity, race, gender, religion, sexual orientation, and ability status, with harmful effects for student well-being [49]. In this context, the promotion of academic relational civility is of increasing importance.

The promotion of academic relational civility on college campuses could foster basic relational sensitivities and skills among university students that help them to develop more positive relationships that contribute to well-being at the university and hopefully, beyond (e.g., in the world of work and society more broadly). University students represent future global citizens and societal leaders who will impact the relational climate of their organizations, families, and societies and the tone and methods of political dialogue [50]. As university students, they have the potential to join with other students to produce social transformation, locally and globally, with the Civil Rights and Black Lives matter movements in the United States, apartheid divestment in South Africa, the Velvet revolution in Prague, and student uprising in Iran and Bejing representing just a few examples [51]. With the speed and vast reach of social media today, student voice can now exert a rapid and broad impact characterized by both civility and incivility [52,53]. 
Out of concern for the impact of relational incivility on the well-being of college students and building on evidence that workplace relational civility [54] is positively correlated with hedonic and eudaimonic well-being [41] among workers, Di Fabio [55] developed the construct and measure of academic relational civility to assess relational quality as a basis for flourishing in the academic setting.

Drawing upon a variety of theoretical perspectives, including positive psychology [56], relational cultural theory [57,58], and the relational theory of working [2], Di Fabio [55] conceptualized relational civility as encompassing respect and care for oneself and others, sensitivity to the needs of others, interest and capacity to communicate one's views to others and kind actions toward others. Civility includes treating others with dignity and behaving in ways that allow people to live and work together in peace and mutual respect. While initially conceptualized with regard to the workplace, the construct and measure were designed to be relevant for varied settings [54]. Di Fabio [55] identified three dimensions for academic relational civility, which are parallel to those identified in the workplace and are supported by factor analysis: relational decency in the academic environment involves relationships based on decency, characterized by respect for self and others (including friends, classmates, staff and professors), calm and respectful self-assertion, and the ability to express one's convictions without aggression; relational culture in the academic environment includes politeness, kindness, recognition of accomplishments, and courtesy in relational behavior; and relational readiness or the presence of individual capacities to engage with civility in the academic environment includes sensitivity toward others (responding to the needs of others in a timely and sensitive way), the ability to accurately perceive and interpret the emotions of others, concern for others, awareness of others' reactions, demonstrating empathy, and showing compassion).

From a primary prevention perspective $[9,17,59-62]$ interventions that enhance resources associated with well-being should be fostered prior to the emergence of difficulties [11-13,41]. Positive relationships, including academic relational civility [55], represent one important category of resources that could be promoted to enhance well-being and sustainability $[11,12,31,55,63]$. While academic civility appears to be a promising construct that can be measured reliably and with validity, further research is needed to evaluate its significance. An important first step is to verify its relationship with well-being among university students.

\section{Aim and Hypotheses}

The aim of the present study was to contribute to the psychology of sustainability $[11,12]$ by examining the relationship between academic relational civility and indices of well-being, both hedonic and eudaimonic. Across all analyses, we first controlled for the effects of personality traits to assess whether the construct of academic relational civility, which is viewed as modifiable, contributes to well-being beyond the contribution of more stable personality traits.

Based upon prior research and theory, the following hypotheses were put forth.

H1: After controlling for the effects of personality traits, academic relational civility will be significantly associated with indices of hedonic well-being, including a positive relationship with positive affect, an inverse relationship with negative affect, and a positive relationship with life satisfaction.

H2: After controlling for the effects of personality traits, academic relational civility will be positively and significantly associated with indices of eudaimonic well-being, including meaning in life, and flourishing.

\section{Material and Methods}

\subsection{Participants}

Two hundred and forty one Italian psychology students (undergraduate and Master's degree) at a university in the center of Italy were involved in the study. With regard to gender, $37.09 \%$ of the 
participants were men and $62.91 \%$ were women. The participants' age ranged from 19 to 28 years $(M=24.02, S D=4.55)$. The participants were mainly White Italians from middle-class backgrounds.

\subsection{Measures}

Big Five Questionnaire (BFQ). The Big Five Questionnaire (BFQ) [64] was administered to evaluate personality traits. The BFQ is composed of 132 items with a 5-point Likert scale response format, ranging from $1=$ Absolutely false to $5=$ Absolutely true. The questionnaire assesses five personality traits: extraversion (example of item: "It's easy for me to talk to people I do not know"); agreeableness (example of item: "I almost always know how to meet the needs of others"); conscientiousness (example of item: "Before giving a job, I spend a lot of time reviewing it"); emotional stability (example of item: "Usually it does not happen to me to react exaggerated even to strong emotions"); and openness (example of item: "Every novelty fascinates me"). With regard to reliability, Cronbach's alpha coefficients were the following: 0.81 for extraversion, 0.73 for agreeableness, 0.81 for conscientiousness, 0.90 for emotional stability, and 0.75 for openness. Regarding convergent validity, the five personality traits of BFQ have demonstrated robust correlations with analogous scales of the NEO Personality Inventory Revised (NEO-PI-R) [32] and with the Stait-Trait Anxiety Inventory, Form $x$ (STAI) [65]. Concerning divergent validity, the BFQ factors did not show significant correlations with the Wechsler Adult Intelligence Scale (WAIS) [66]).

Academic Relational Civility Scale. The newly developed and validated 26-item Academic Relational Civility Scale (ARCS) [55] was used to evaluate the three dimensions of academic relational civility: relational readiness (RR, examples of item: "I was interested in the emotional condition of others"; "Others were interested in my emotional condition"), relational culture (RCu, examples of item: "I was polite toward others"; "Others were polite toward me"), and relational decency (RD, examples of item: "I communicated my disagreement with others without being aggressive"; "Others communicated their disagreement with me without being aggressive"). Each dimension contains items relating to one's perception of self and one's perceptions of others. Part A concerns the individual's perception of himself or herself with regard to a particular aspect of relational functioning (example of item: "I respected the opinions of others"), while Part B concerns the individual's perception of others with regard to the same aspect of functioning (example of item: "Others respected my opinions"). The RR dimension contains 5 items for Part A and 5 items for Part B. RCu contains 4 items for Part A and 4 for Part B, and RD consists of 4 items for Part A and 4 items for Part B. Scores are computed for the Part A and Part B items for each dimension and then summed, yielding an overall score for each part of the ARCS (Part A and Part B) and a total score. The participants in this study were asked to describe their relationships with others (friends, classmates, staff and professors) over the past 3 months, and then to describe their perception of others' (friends, classmates, staff and professors) relationships or interactions with them over the same time period. The items had a response format on a 5-point Likert scale ranging from $1=$ Not at all to $5=$ A great deal. The Cronbach's alpha coefficients for the three dimensions for Part A were 0.81 for relational readiness (Factor 1A); 0.78 for relational culture (Factor 2A); and 0.76 for relational decency (Factor 3A). The Cronbach's alpha coefficients for the three dimensions for Part B were: 0.87 for relational readiness (Factor 1B); 0.89 for relational culture (Factor 2B); and 0.83 for relational decency (Factor 3B). The Cronbach's alpha coefficients for the total score were 0.85 for Part A and 0.90 for Part B. Concerning construct validity, the ARCS demonstrated positive and statistically significant correlations with the Prosocial Organizational Behaviors Scale (POBS) [67]; and the Positive Relational Management Scale [68].

Positive and Negative Affect Schedule (PANAS). The Italian version [28] of the Positive and Negative Affect Schedule (PANAS) [19] was administered to evaluate positive affect (PA) and negative affect (NA) as indices of hedonic well-being. The PANAS includes 20 adjectives with 10 referring to positive affect (PA; e.g., concentrating and inspired) and 10 to negative affect (NA; e.g., scared and nervous). Participants are asked to point out how they generally feel based on a 5-point Likert scale ranging from $1=$ Very slightly or not at all to $5=$ Extremely. Regarding reliability the Cronbach's 
alpha coefficients were 0.72 for positive affect and 0.83 for negative affect. With regard to construct validity, relationships with measures of personality have been previously documented [32], including positive associations between PA and extraversion and between NA and neuroticism. Furthermore PA correlated inversely with the Center for Epidemiological Studies Depression Scale (CES-D) [69], with NA correlating positively with the CES-D.

Satisfaction With Life Scale (SWLS). The Italian version of the Satisfaction With Life Scale (SWLS) [22] by Di Fabio and Gori [70] was administered to measure life satisfaction as a component of hedonic well-being. The scale is composed of five items (e.g., "In most ways my life is close to my ideal", "So far I have gotten the important things I want in life"), with a response format on a 7-point Likert scale, ranging from $1=$ Strongly disagree to $7=$ Strongly agree. Regarding reliability, the Cronbach's alpha coefficient was 0.85 . With regard to construct validity, Di Fabio and Gori [70] documented positive correlations between the Italian version of the SWLS and the Rosenberg Self-Esteem Scale [71].

Meaning in Life Measure. The Italian version [72] of the Meaningful Life Measure (MLM) [23] was administered to measure meaning in life as a component of eudaimonic well-being. The questionnaire includes 23 items, which are rated on a 7-point Likert scale ranging from $1=$ strongly disagree to $7=$ strongly agree. The MLM distinguishes five dimensions: exciting life (e.g., "My life interests and excites me"), accomplished life (e.g., "I have been very successful in achieving certain things"), principled life (e.g., "I have a system or framework that allows me to truly understand my being alive"), purposeful life (e.g., "In my life I have very clear goals and aims"), and valued life (e.g., "My life is worthwhile"). The Cronbach's alpha coefficients were 0.85 for exciting life; 0.87 for accomplished life; 0.86 for principled life, 0.85 for purposeful life; and 0.84 for valued life. The alpha value for the total score was 0.85 . With regard to the concurrent validity of the Italian version of the MLM, positive relationships were found with life satisfaction and positive affect and an inverse relationship was found with negative affect [72].

Flourishing Scale (FS). The Italian version of the Flourishing Scale (FS) [24] in the [73] was administered to detect flourishing as a component of eudaimonic well-being. The FS is composed of eight items with the response format being a 6-point Likert scale ranging from $1=$ Strongly disagree to $7=$ Strongly agree. Examples of items include "I am engaged and interested in my daily activities", "I actively contribute to the happiness and well-being of others", and "I am a good person and live a good life". The FS presented a unidimensional structure and the Cronbach's alpha coefficient was 0.88 . Positive and statistically significant correlations of the Italian version of the FS with the Meaningful Life Measure [23], the Authenticity Scale (AS) [74], the Satisfaction with Life Scale (SWLS) [22] and the Positive Affect (PA) scale of the Positive Affect and Negative Affect Scales PANAS [19] have offered evidence for validity of the FS.

\subsection{Procedure}

The questionnaires were administered to university students in a group setting by trained psychologists in agreement with the requirements of privacy and informed consent of Italian law (Law Decree DL-196/2003) and the ethical standards for research of the Declaration of Helsinki revised in Fortaleza (World Medical Association [WMA]). Students participated in the study in a voluntary manner, and they received no compensation. The order of administration was counterbalanced, changing the sequence of administration of the questionnaires to control for the effects of presentation order. After having distributed the questionnaires, the administrators explained to the participants that there were no right or wrong answers and invited them to respond as accurately as possible to the items of the questionnaire. The students were recruited as volunteers for the study during psychology classes that are offered for students across all level of undergraduate study, and no compensation was offered for their participation.

\section{Results}

Descriptive statistics and correlations are reported in Table 1. 
Table 1. Descriptive statistics and correlations $(N=241)$.

\begin{tabular}{|c|c|c|c|c|c|c|c|c|c|c|c|c|c|c|}
\hline & 1 & 2 & 3 & 4 & 5 & 6 & 7 & 8 & 9 & 10 & 11 & 12 & $M$ & $D S$ \\
\hline 1. BFQ E & - & & & & & & & & & & & & 76.28 & 8.95 \\
\hline 2. BFQ A & $0.18^{* *}$ & - & & & & & & & & & & & 81.12 & 8.62 \\
\hline 3. BFQ C & $0.14 *$ & 0.13 * & - & & & & & & & & & & 82.26 & 9.66 \\
\hline 4. BFQ ES & $0.18^{* *}$ & $0.38^{* *}$ & $0.18 * *$ & - & & & & & & & & & 69.28 & 12.12 \\
\hline 5. BFQ O & $0.26^{* *}$ & $0.51 * *$ & $0.13^{*}$ & $0.23 * *$ & - & & & & & & & & 83.71 & 9.96 \\
\hline 6. ARCS Part A & $0.21^{* *}$ & $0.35^{* *}$ & $0.25 * *$ & $0.19^{* *}$ & 0.30 ** & - & & & & & & & 33.94 & 10.69 \\
\hline 7. ARCS Part B & $0.33^{* *}$ & $0.39^{* *}$ & 0.05 & $0.21^{* *}$ & $0.26^{* *}$ & $0.58^{* *}$ & - & & & & & & 37.13 & 9.14 \\
\hline 8. PA & $0.61^{* *}$ & $0.15^{*}$ & $0.24 * *$ & $0.16^{* *}$ & $0.34^{* *}$ & $0.34^{* *}$ & $0.38^{* *}$ & - & & & & & 35.15 & 5.21 \\
\hline 9. NA & $-0.14^{*}$ & $-0.34 * *$ & $-0.16^{* *}$ & $-0.43 * *$ & $-0.22 * *$ & $-0.16^{* *}$ & $-0.34^{* *}$ & $-0.18^{* *}$ & - & & & & 21.19 & 7.47 \\
\hline 10. SWLS & $0.38^{* *}$ & $0.31^{* *}$ & 0.05 & $0.27^{* *}$ & $0.15^{*}$ & $0.27 * *$ & $0.51^{* *}$ & $0.48^{* *}$ & $-0.37^{* *}$ & - & & & 23.52 & 6.71 \\
\hline 11. MLM & $0.49^{* *}$ & $0.31 * *$ & $0.21^{* *}$ & $0.30 * *$ & $0.46^{* *}$ & $0.44^{* *}$ & $0.55^{* *}$ & $0.68^{* *}$ & $-0.39 * *$ & $0.66^{* *}$ & - & & 116.64 & 18.17 \\
\hline 12. FS & $0.46^{* *}$ & $0.34^{* *}$ & $0.17^{* *}$ & $0.29 * *$ & $0.41^{* *}$ & $0.48^{* *}$ & $0.56^{* *}$ & $0.62 * *$ & $-0.33^{* *}$ & $0.62 * *$ & $0.77^{* *}$ & - & 42.88 & 7.94 \\
\hline
\end{tabular}

${ }^{*} p<0.05 . * *<0.01$. BFQ $=$ Big Five Questionnaire; ARCS = Academic Relational Civility Scale; PANAS PA = PANAS Positive Affects; PANAS NA $=$ PANAS Negative affects; SWLS = Satisfaction With Life Scale; MLM = Meaning in Life Measure; FS = Flourishing Scale. 
Hierarchical regression analyses were conducted to assess the study hypotheses. Table 2 presents the findings of five separate hierarchical regression models, with positive affect, negative affect, life satisfaction, meaning in life and flourishing serving as the five separate dependent variables. Across all analyses, personality traits were entered at step one and academic relational civility was entered at the second step.

Table 2. Hierarchical regression. The contributions of personality traits (first step) and Academic relational civility (second step) to positive affect (PA), negative affect (NA), life satisfaction (SWLS), meaning in life (MLM) and flourishing (FS) $(N=241)$.

\begin{tabular}{cccccc}
\hline & PA & NA & SWLS & MLM & FS \\
\hline & $\boldsymbol{\beta}$ & $\boldsymbol{\beta}$ & $\boldsymbol{\beta}$ & $\boldsymbol{\beta}$ & $\boldsymbol{\beta}$ \\
\hline Step 1 & & & & & \\
BFQ Extraversion & $0.54^{* * *}$ & -0.05 & $0.33^{* * *}$ & $0.36^{* * *}$ & $0.34^{* * *}$ \\
BFQ Agreeableness & $0.11^{* *}$ & $-0.20^{* *}$ & $0.24^{* *}$ & 0.00 & 0.08 \\
BFQ Conscientiousness & $0.16^{* *}$ & $-0.14^{*}$ & 0.01 & $0.15^{* *}$ & $0.11^{*}$ \\
BFQ Emotional stability & $0.09^{* * *}$ & $-0.30^{* * *}$ & $0.14^{*}$ & $0.20^{* *}$ & $0.16^{* *}$ \\
BFQ Openness & $0.21^{* * *}$ & -0.06 & 0.09 & $0.31^{* * *}$ & $0.23^{* * *}$ \\
Step 2 & & & & & \\
ARCS Part A & $0.10^{* *}$ & $-0.09^{* *}$ & 0.09 & 0.07 & $0.13^{*}$ \\
ARCS Part B & $0.16^{* * *}$ & $-0.28^{* * *}$ & $0.44^{* * *}$ & $0.36^{* * *}$ & $0.36^{* * *}$ \\
$R^{2}$ step 1 & $0.44^{* * *}$ & $0.24^{* * *}$ & $0.22^{* * *}$ & $0.40^{* * *}$ & $0.34^{* * *}$ \\
$\Delta R^{2}$ step 2 & $0.04^{*}$ & $0.05^{* *}$ & $0.13^{* * *}$ & $0.13^{* * *}$ & $0.16^{* * *}$ \\
$R^{2}$ total & $0.48^{* * *}$ & $0.29^{* * *}$ & $0.35^{* * *}$ & $0.53^{* * *}$ & $0.50^{* * *}$ \\
\hline
\end{tabular}

${ }^{*} p<0.05 .{ }^{* *} p<0.01 .{ }^{* * *} p<0.001$. BFQ = Big Five Questionnaire; ARCS = Academic Relational Civility Scale; PANAS PA = PANAS Positive Affects; PANAS NA = PANAS Negative affects; SWLS = Satisfaction With Life Scale; MLM = Meaning in Life Measure; FS = Flourishing Scale.

For the first regression analysis explaining positive affect as a component of hedonic well-being, personality traits accounted for $44 \%$ of the variance at step one. At the second step, academic relational civility added $4 \%$ variance, with the overall model accounting for $48 \%$ of the variance.

For the second analysis with negative affect as the dependent variable, personality traits explained $24 \%$ of the variance at step one. For step two, academic relational civility added $5 \%$ variance, with the overall model overall explaining $29 \%$ of the variance.

For the third analysis, personality traits accounted for $22 \%$ of the variance at step one in explaining life satisfaction. At step two, academic relational civility added $13 \%$ variance, with the overall model explaining $35 \%$ of the variance for life satisfaction.

For the fourth analysis with meaning in life as a component of eudaimonic well-being, personality traits explained $40 \%$ of the variance at step one and at step two, academic relational civility added $13 \%$ variance, with the overall model accounting for $53 \%$ of the variance for meaningful life.

For the final analysis explaining flourishing as an index of eudaimonic well-being, personality traits explained $34 \%$ of the variance at step one. Academic relational civility added $16 \%$ to the variance in the second step, with the overall model explaining $50 \%$ of the variance for flourishing.

\section{Discussion}

The aim of this study was to explore the association between academic relational civility and both hedonic well-being (positive affect, negative affect and life satisfaction) and eudaimonic well-being (meaning in life and flourishing) among university students, after controlling for personality traits. In relation to sustainable development goals, an academic environment characterized by relational civility could contribute to the third goal of good health and well-being and also to the fourth goal concerning the quality of education and academic success by improving the quality of the relationships in the academic context. Furthermore the enhancement of academic relational civility could potentially promote personal relational skills, which from a primary prevention perspective could contribute to 
the construction of a culture of decency in society and at work, thereby advancing movement towards the eighth sustainable development goal related to decent work.

The analyses supported our hypotheses regarding the relationship between academic relational civility and indices of hedonic well-being after controlling for the contribution of personality traits. Our results add to the existing literature [41] that has established a relationship between hedonic well-being and relational civility among workers by documenting the association of ARC with the activation of positive affect [19]. The finding of a negative relationship between academic relational civility and negative affect replicates, for university students, the association found between relational civility in the workplace and the activation of negative affect [19]. The finding that relational civility is related to life satisfaction among university students also replicates findings for workers [41]. With regard to the contribution of ARC to both positive and negative affect, the findings (beta weights) revealed that Part B, the perception of others' relational civility, contributed more to the explanatory power of the construct than Part A, the self-assessment of one's own level of relational civility. The contribution of academic relational civility, especially the perception of others level of ARC to well-being among university students, appears somewhat stronger for global life satisfaction than for the experience of positive or negative affect [22].

Our hypothesis that academic relational civility would be related to indices of eudaimonic well-being was also supported. Similar to the findings for workers, relational civility in the academic setting, especially the perception of others' level of ARC, is associated with students' level of meaning in life and their expressed capacity to identify their authentic meaning and pursue meaningful life goals [23]. The finding of a positive relationship between academic relational civility and flourishing extends previous findings documenting an association between relational civility and eudaimonic well-being among workers [41], which had not included flourishing in the assessment of eudaimonic well-being. Among university students in this study, greater relational civility, especially in regard to the perception of others' ARC, was associated with eudaimonic well-being in terms of flourishing characterized by feelings of optimism, sense of purpose and satisfying and successful relationships [24]. The finding that relational civility both in the workplace and university setting is associated with two kinds of well-being, beyond the influence of personality traits, suggests that societal attention to promoting relational civility is important, especially during these times of tension and rising incidents of incivility [49].

While the contribution of Part A (students' perceptions of their own relational civility) for flourishing was statistically significant, it is interesting to note that students' reports of their own well-being across all dimensions was more strongly associated with their perceptions of others than with their appraisal of their own relational civility. This was also observed in the findings with workers [41]. It seems that students and workers can experience well-being, even if they do not perceive themselves as relating in civil ways. The finding that the perception of one's own relationship civility is significant for flourishing makes sense, since this is the only dimension of well-being that considers the quality of relationships. Since the overall climate of relational civility depends on the relational behavior of all individuals; however, attention may need to be increased to foster student and worker perspective-taking and their awareness of their impact on others.

Overall, academic relational civility demonstrated a stronger association with eudaimonic well-being than with the positive and negative affect dimensions of hedonic well-being. Regarding hedonic well-being, the association with life satisfaction was more robust than with positive and negative affect, suggesting that academic relational civility, including relational readiness, relational culture, and relational decency, fosters an assessment of one's well-being at the level of life satisfaction, meaning and flourishing. The realization of different aspects of academic relational civility may support student efforts in constructing lives of meaning with a sense of purpose, perceived success in relationships and individual flourishing.

Notwithstanding the contribution of the present study in documenting the association between academic relational civility and both hedonic and eudaimonic well-being among university students, 
some limitations should be noted. The participants were a limited sample of Italian university students from a university in the center of Italy and thus, the results are not generalizable to all Italian university students. Future research should therefore include participants from varied geographical areas in Italy as well as in other countries to verify the cross-cultural relevance of the construct. Additionally, the measures were self-reported and were thus subject to biases of self-perception. Correlational data does not indicate causality, so further longitudinal research is needed to assess change over time. Furthermore, the possible moderating role or mediating role of academic relational civility in the relationships between personality traits and both hedonic well-being and eudaimonic well-being could be investigated in future research to better understand the potential causal mechanisms, also taking into consideration the different weights of Part A and Part B of the scale. Further research might also investigate the relationship between academic relational civility and other indices of eudaimonic well-being, such as the subjective experience of eudaimonia [21] and existential fulfillment [75], authenticity [62], as well as in relation to indices of academic success, progress in career development, and persistence in university studies.

Given the experiences of incivility arising on college campuses related to student differences in social class, ethnicity, race, gender, religion and immigrant status [49], it is also be important to study the determinants of academic relational civility in relation to student demographics and the level of diversity present at the university and across society. How to engage students, staff, and faculty in the development of relational civility and their concern that they contribute to the level of civility on campus is also important. Further research might also seek to identify aspects of the university environment that contribute to the experience of academic relational civility and aspects that reward the demonstration of academic relational civility.

Despite the limitations and the need for further research, our results advance the related body of literature by documenting the relationship of academic relational civility, especially student perceptions of others' civility, with well-being overall and eudaimonic well-being, in particular. In contrast to personality traits that are considered generally stable in research findings [32], evidence suggests that academic relational civility can be increased through specific interventions [55]. If further research confirms the value of this construct and intervention, universities may offer initiatives to enhance student relational civility in efforts to enhance student well-being and to prepare them for meeting the challenges of contemporary life and to give them lives with meaning, purpose and relational satisfaction.

\section{Conclusions}

The well-being of individuals is one of the 17 sustainable development goals of the United Nations [10] that is considered essential for promoting world sustainable development and to ensure prosperity for all. In recognition of this agenda, building individual strengths and resources is important from a primary prevention perspective for promoting well-being and a flourishing society $[9,11-13,17,62]$. In the academic environment, positive relationships are central to student well-being and success [42,44]. The construct of academic relational civility [55] represents a specific and expanded conceptualization of positive relationships defined by relational readiness, relational culture and relational decency in the academic setting. This study examined the relationship of academic relational civility with well-being for university students, in recognition that these skills can be developed with specific intervention strategies [55]. If the results of the present study are confirmed in future research, academic relational civility could represent a psychological resource that could be promoted more intentionally, is potentially sustainable, and could grow over the course of development for the promotion of well-being among young adults and enhance their capacity to respond effectively to the challenges of contemporary life.

Author Contributions: A.D.F. conceptualized the study and the theoretical framework, with M.E.K. helping to select measures. A.D.F. collected the data and, with M.E.K., wrote the methods and results. Then, the authors wrote the discussion together and read and edited the manuscript with several rounds of revisions. 
Conflicts of Interest: The authors declare no conflict of interest.

\section{References}

1. Landy, F.J.; Conte, J.M. Work in the 21st Century, Binder Ready Version: An Introduction to Industrial and Organizational Psychology; John Wiley \& Sons: Hoboken, NJ, USA, 2016; ISBN 10: 1118291204.

2. Blustein, D.L. A relational theory of working. J. Voc. Behav. 2011, 79, 1-17. [CrossRef]

3. Di Fabio, A. Intrapreneurial Self-Capital: A new construct for the 21st century. J. Employ. Couns. 2014, 51, 98-111. [CrossRef]

4. Guichard, J. Career guidance, education, and dialogues for a fair and sustainable human development. In Proceedings of the Inaugural Conference of the UNESCO Chair of Lifelong Guidance and Counselling, University of Wroclaw, Wroclaw, Poland, 26-27 November 2013.

5. Peiró, J.M. Stress and coping at work: New research trends and their implications for practice. In The Individual in the Changing Working Life; Näswall, K., Hellgren, J., Sverke, M., Eds.; Cambridge University Press: Cambridge, UK, 2008; pp. 284-310, ISBN 0521879469.

6. Peiró, J.M. Sustainable well-being at work. In Proceedings of the First International Cross-Cultural Conference "Healthier Societies Fostering Healthy Organizations: A Cross-Cultural Perspective", Department of Education and Psychology, University of Florence, Florence, Italy, 26-27 May 2017.

7. Savickas, M.L. Career Counseling; American Psychological Association: Washington, DC, USA, 2011; ISBN 9781433809804.

8. Van den Heuvel, M.; Demerouti, E.; Bakker, A.B.; Schaufeli, W.B. Personal resources and work engagement in the face of change. Contemp. Occup. Health Psychol. 2010, 1, 124-150. [CrossRef]

9. Di Fabio, A.; Kenny, E.M. From decent work to decent lives: Positive Self and Relational Management (PS\&RM) in the twenty-first century. Front. Psychol. Sect. Org. Psychol. 2016, 7, 361, doi:10.3389/fpsyg.2016.00361. [CrossRef]

10. United Nations. Sustainable Development Goals. 2015. Available online: http://www.un.org/ sustainabledevelopment/sustainable-development-goals / (accessed on 20 March 2018).

11. Di Fabio, A. The psychology of sustainability and sustainable development for well-being in organizations. Front. Psychol. Sect. Org. Psychol. 2017, 8, 1534. [CrossRef] [PubMed]

12. Di Fabio, A. Positive Healthy Organizations: Promoting well-being, meaningfulness, and sustainability in organizations. Front. Psychol. Sect. Org. Psychol. 2017, 8, 1938. [CrossRef] [PubMed]

13. World Health Organization. World Health Organization Definition of Health. 1998. Available online: http:/ / www.who.ch/aboutwho/definition.htm (accessed on 20 March 2018).

14. Di Fabio, A.; Kenny, M.E. Promoting well-being: The contribution of emotional intelligence. Front. Psychol. Sect. Org. Psychol. 2016, 7, 1182. [CrossRef] [PubMed]

15. World Health Organization. Workers' Health: Global Plan of Action. Sixtieth World Health Assembly. Available online: http://www.who.int/occupational_health/publications/global_plan/en/ (accessed on 20 March 2018).

16. Seligman, M.E.P. Positive psychology, positive prevention, and positive therapy. In Handbook of Positive Psychology; Snyder, C.R., Lopez, S.J., Eds.; Oxford University Press: Oxford, UK, 2002; pp. 3-9, ISBN 978-0195135336.

17. Kenny, M.E.; Hage, S.M. The next frontier: Prevention as an instrument of social justice. J. Prim. Prev. 2009, 30, 1-10. [CrossRef] [PubMed]

18. Seligman, M.E.; Csikszentmihalyi, M. Positive psychology: An introduction. Am. Psychol. 2000, 55, 5-14. [CrossRef] [PubMed]

19. Watson, D.; Clark, L.A.; Tellegen, A. Development and validation of brief measures of positive and negative affect: The PANAS scales. J. Pers. Soc. Psychol. 1988, 54, 1063-1070. [CrossRef] [PubMed]

20. Ryan, R.M.; Deci, E.L. To be happy or to be self-fulfilled: A review of research on hedonic and eudaimonic well-being. Annu. Rev. Psychol. 2001, 52, 141-166. [CrossRef] [PubMed]

21. Waterman, A.S.; Schwartz, S.J.; Zamboanga, B.L.; Ravert, R.D.; Williams, M.K.; Bede Agocha, V.; Kim, S.Y.; Donnellan, M.B. The Questionnaire for Eudaimonic Well-Being: Psychometric properties, demographic comparisons, and evidence of validity. J. Posit. Psychol. 2010, 5, 41-61. [CrossRef] 
22. Diener, E.D.; Emmons, R.A.; Larsen, R.J.; Griffin, S. The satisfaction with life scale. J. Pers. Assess. 1985, 49, 71-75. [CrossRef] [PubMed]

23. Morgan, J.; Farsides, T. Measuring meaning in life. J. Happiness Stud. 2009, 10, 197-214. [CrossRef]

24. Diener, E.; Wirtz, D.; Tov, W.; Kim-Prieto, C.; Choi, D.W.; Oishi, S.; Biswas-Diener, R. New well-being measures: Short scales to assess flourishing and positive and negative feelings. Soc. Indic. Res. 2010, 97, 143-156. [CrossRef]

25. Bruck, C.S.; Allen, T.D. The relationship between big five personality traits, negative affectivity, type a behavior, and work-family conflict. J. Voc. Behav. 2003, 63, 457-472. [CrossRef]

26. Di Fabio, A.; Saklofske, D.H. Promoting individual resources: The challenge of trait emotional intelligence. Pers. Individ. Difer. 2014, 65, 19-23. [CrossRef]

27. Suldo, S.M.; Minch, D.R.; Hearon, B.V. Adolescent life satisfaction and personality characteristics: Investigating relationships using a five factor model. J. Happiness Stud. 2015, 16, 965-983. [CrossRef]

28. Terracciano, A.; McCrae, R.R.; Costa, P.T., Jr. Factorial and construct validity of the Italian Positive and Negative Affect Schedule (PANAS). Eur. J. Psychol. Assess. 2003, 19, 131-141. [CrossRef] [PubMed]

29. Halama, P. Relationship between meaning in life and the big five personality traits in young adults and the elderly. Stud. Psychol. 2005, 47, 167-178.

30. Steger, M.F.; Kashdan, T.B.; Sullivan, B.A.; Lorentz, D. Understanding the search for meaning in life: Personality, cognitive style, and the dynamic between seeking and experiencing meaning. J. Pers. 2008, 76, 199-228. [CrossRef] [PubMed]

31. Villieux, A.; Sovet, L.; Jung, S.C.; Guilbert, L. Psychological flourishing: Validation of the French version of the Flourishing Scale and exploration of its relationships with personality traits. Pers. Individ. Difer. 2016, 88, 1-5. [CrossRef]

32. Costa, P.T.; McCrae, R.R. NEO PI-R Professional Manual; Psychological Assessment Resources: Odessa, FL, USA, 1992; ISBN 9789997924452.

33. Extremera, N.; Ruiz-Aranda, D.; Pineda-Galán, C.; Salguero, J.M. Emotional intelligence and its relation with hedonic and eudaimonic well-being: A prospective study. Pers. Individ. Difer. 2011, 51, 11-16. [CrossRef]

34. Di Fabio, A.; Palazzeschi, L. Hedonic and eudaimonic well-being: The role of resilience beyond fluid intelligence and personality traits. Front. Psychol. 2015, 6, 1367. [CrossRef] [PubMed]

35. Di Fabio, A.; Kenny, M.E.; Minor, K. School-based research and practice in Italy. In Handbook of Positive Psychology in the Schools, 2nd ed.; Furlong, M.J., Gilman, R., Huebner, E.S., Eds.; Taylor and Francis, Routledge: New York, NY, USA, 2014; pp. 450-464, ISBN 978-0-415-62185-4.

36. Blustein, D.L. The Psychology of Working: A New Perspective for Counseling, Career Development, and Public Policy; Lawrence Erlbaum Associates: Mahwah, NJ, USA, 2006; ISBN 978-0805858792.

37. Blustein, D. The Psychology of Working: A New Perspective for a New Era; Oxford Handbook Online: Oxford, UK, 2013. [CrossRef]

38. Ferguson, S.J. Goodwin Optimism and well-being in older adults: The mediating role of social support and perceived control. Int. J. Aging Hum. Dev. 2010, 71, 43-68. [CrossRef] [PubMed]

39. Gallagher, E.N.; Vella-Brodrick, D.A. Social support and emotional intelligence as predictors of subjective well-being. Pers. Individ. Difer. 2008, 44, 1551-1561. [CrossRef]

40. Kalpana Rani, E. Perceived social support and psychological well-being: Testing the unique association and gender differences among young working adults. Int. J. Indian Psychol. 2016, 3, 99-113. Available online: http:/ / oaji.net/articles/2016/1170-1454050385.pdf (accessed on 20 March 2018).

41. Di Fabio, A.; Giannini, M.; Loscalzo, Y.; Palazzeschi, L.; Bucci, O.; Guazzini, A.; Gori, A. The challenge of fostering healthy organizations: An empirical study on the role of workplace relational civility in acceptance of change, and well-being. Front. Psychol. Sect. Org. Psychol. 2016, 7, 1748. [CrossRef] [PubMed]

42. Cotton, S.J.; Dollard, M.F.; De Jonge, J. Stress and student job design: Satisfaction, well-being, and performance in university students. Int. J. Stress Manag. 2002, 9, 147-162. [CrossRef]

43. Di Fabio, A. Beyond fluid intelligence and personality traits in social support: The role of ability based emotional intelligence. Front. Psychol. 2015, 6, 395. [CrossRef] [PubMed]

44. Lee, R.L.; Loke, A.J. Health-promoting behaviors and psychosocial well-being of university students in Hong Kong. Public Health Nurs. 2005, 22, 209-220. [CrossRef] [PubMed]

45. Friedlander, L.J.; Reid, G.J.; Shupak, N.; Cribbie, R. Social support, self-esteem, and stress as predictors of adjustment to university among first-year undergraduates. J. Coll. Stud. Dev. 2007, 48, 259-274. [CrossRef] 
46. Kong, F.; Zhao, J.; You, X. Self-esteem as mediator and moderator of the relationship between social support and subjective well-being among Chinese university students. Soc. Indic. Res. 2013, 112, 151-161. [CrossRef]

47. Wilcox, P.; Winn, S.; Fyvie-Gauld, M. 'It was nothing to do with the university, it was just the people': The role of social support in the first-year experience of higher education. Stud. High. Educ. 2005, 30, 707-722. [CrossRef]

48. Clark, C.M.; Springer, P.J. Thoughts on incivility: Student and faculty perceptions of uncivil behavior in nursing education. Nurs. Educ. Perspect. 2007, 28, 93-97. [CrossRef] [PubMed]

49. Weeks, K.M. In Search of Civility: Confronting Incivility on the College Campus; Morgan James Publishing: New York, NY, USA, 2011; ISBN 1600379079.

50. Hazelkkorn, E. Is the public good role of higher education under attack? Int. High. Educ. 2017, 91, 2-3. [CrossRef]

51. Astor, M. 7 Times in history when students turned to activism. The New York Times, 5 March 2018. Available online: https://www.nytimes.com/2018/03/05/us/student-protest-movements.html (accessed on 31 May 2018).

52. Martínez Alemán, A.M.; Wartman, K.L. Online Social Networking on Campus: Understanding What Matters in Student Culture; Routledge/Francis Taylor Group: New York, NY, USA, 2009; ISBN 978-0521669375.

53. Rowan-Kenyon, H.T.; Martínez Alemán, A.M.; Gin, K.; Blakeley, B.; Gismondi, A.; Lewis, J.; McCready, A.; Zepp, D.; Knight, S. Social Media in Higher Education; ASHE Higher Education Report; John Wiley: San Francisco, CA, USA, 2016; Volume 42.

54. Di Fabio, A.; Gori, A. Assessing Workplace Relational Civility (WRC) with a new multidimensional "mirror" measure. Front. Psychol. Sect. Org. Psychol. 2016, 7, 890. [CrossRef] [PubMed]

55. Di Fabio, Academic Relational Civility Scale. Couns. G. Ital. Ric. Appl. 2018, 11. [CrossRef]

56. Fredrickson, B.L.; Losada, M.F. Positive affect and the complex dynamics of human flourishing. Am. Psychol. 2005, 60, 678-686. [CrossRef] [PubMed]

57. Miller, J.B. Toward a New Psychology of Women; Beacon Press: Boston, MA, USA, 1976; ISBN 0807029092.

58. Miller, J.B. Preface. In The Complexity of Connection; Jordan, J., Hartling, L., Walker, M., Eds.; Guilford Press: New York, NY, USA, 2004; pp. 1-4. ISBN 1593850255.

59. Di Fabio, A.; Kenny, M.E. Promoting emotional intelligence and career decision making among Italian high school students. J. Career Assess. 2011, 19, 21-34. [CrossRef]

60. Di Fabio, A.; Kenny, M.E. The contribution of emotional intelligence to decisional styles among Italian high school students. J. Career Assess. 2012, 20, 404-414. [CrossRef]

61. Di Fabio, A.; Kenny, M.E. The contributions of emotional intelligence and social support for adaptive career progress among Italian youth. J. Career Dev. 2015, 42, 48-49. [CrossRef]

62. Hage, S.M.; Romano, J.L.; Conyne, R.K.; Kenny, M.; Matthews, C.; Schwartz, J.P.; Waldo, M. Best practice guidelines on prevention practice, research, training, and social advocacy for psychologists. Couns. Psychol. 2007, 35, 493-566. [CrossRef]

63. Di Fabio, A.; Palazzeschi, L.; Bucci, O. In an unpredictable and changing environment: Intrapreneurial Self-Capital as a key resource for life satisfaction and flourishing. Front. Psychol. Sect. Org. Psychol. 2017, 8, 1819. [CrossRef] [PubMed]

64. Caprara, G.V.; Barbaranelli, C.; Borgogni, L. BFQ: Big Five Questionnaire, 2nd ed.; Giunti O.S.: Firenze, Italy, 1993; ISBN 9788809400672.

65. Spielberger, C.D.; Gorsuch, R.L.; Lushene, R.E. State-Trait Anxiety Inventory; Consulting Psychology Press: Palo Alto, CA, USA, 1968; ISBN 8809400933.

66. Wechsler, D. Manual for the Wechsler Adult Intelligence Scale-Revised; The Psychological Corporation: New York, NY, USA, 1981; ISBN B0006YQQPS.

67. McNeely, B.L.; Meglino, B.M. The role of dispositional and situational antecedents in prosocial organizational behavior: An examination of the intended beneficiaries of prosocial behavior. J. Appl. Psychol. 1994, 79, 836-844. [CrossRef]

68. Di Fabio, A. Positive Relational Management for healthy organizations: Psychometric properties of a new scale for prevention for workers. Front. Psychol. Sect. Org. Psychol. 2016, 7, 1523. [CrossRef] [PubMed]

69. Radloff, L.S. The CES-D scale: A self-report depression scale for research in the general population. Appl. Psychol. Meas. 1977, 1, 385-401. [CrossRef] 
70. Di Fabio, A.; Gori, A. Measuring adolescent life satisfaction: Psychometric properties of the Satisfaction with Life Scale in a sample of Italian adolescents and young adults. J. Psychoeduc. Assess. 2016, 34, 501-506. [CrossRef]

71. Rosenberg, M. Society and the Adolescent Self-Image; Princeton University Press: Princeton, NJ, USA, 1965; ISBN 978-0691649443.

72. Di Fabio, A. Meaningful life measure: Primo contributo alla validazione della versione italiana [Meaningful life measure: First contribution to the validation of the Italian version]. Couns. G. Ital. Ric. Appl. 2014, 7, 307-315.

73. Di Fabio, A. Fluorishing Scale: Primo contributo alla validazione della versione italiana [Fluorishing Scale: First contribution to the validation of the Italian version]. Couns. G. Ital. Ric. Appl. 2016, 9, doi:10.14605/CS911606. [CrossRef]

74. Wood, A.M.; Linley, P.A.; Maltby, J.; Baliousis, M.; Joseph, S. The authentic personality: A theoretical and empirical conceptualization and the development of the Authenticity Scale. J. Couns. Psychol. 2008, 55, 385-399. [CrossRef]

75. Längle, A.; Orgler, C.; Kundi, M. The Existence Scale: A new approach to assess the ability to find personal meaning in life and to reach existential fulfillment. Eur. Psychother. 2003, 4, 135-146.

(c) 2018 by the authors. Licensee MDPI, Basel, Switzerland. This article is an open access article distributed under the terms and conditions of the Creative Commons Attribution (CC BY) license (http:/ / creativecommons.org/licenses/by/4.0/). 